\title{
Serum high mobility group box-1 and osteoprotegerin levels are associated with peripheral arterial disease and critical limb ischemia in type 2 diabetic subjects
}

\author{
Silvia Giovannini ${ }^{1}$, Giovanni Tinelli ${ }^{2}$, Federico Biscetti ${ }^{3,4}$, Giuseppe Straface ${ }^{5}$, Flavia Angelini ${ }^{4}$, Dario Pitocco ${ }^{6}$,
} Luciana Mucci ${ }^{4,6}$, Raffaele Landolfi6 ${ }^{6}$ and Andrea Flex $x^{4,6^{*}}$

\begin{abstract}
Background: High mobility group box-1 (HMGB-1) is a nuclear protein also acting as inflammatory mediator, whilst osteoprotegerin (OPG), member of tumor necrosis factor receptor superfamily, is indicated as marker of vascular calcification. Peripheral artery disease (PAD) and type 2 diabetes (T2D) are clinical conditions characterized by elevated serum inflammatory markers and vascular calcification enhancement. The aim of this study was to investigate the potential role of HMGB-1, OPG and several inflammatory mediators such as C-reactive protein (HsCRP), tumor necrosis factor-alpha and interleukin-6 (IL-6) on the presence and severity of peripheral artery disease in patients with T2D.

Methods: In this retrospective observational study, we have analyzed HMGB-1, OPG and inflammatory cytokines serum levels in 1393 type 2 diabetic patients with PAD and without PAD (WPAD).

Results: HMGB-1 $(7.89 \pm 15.23 \mathrm{ng} / \mathrm{mL}), \mathrm{OPG}(6.54 \pm 7.76 \mathrm{pmol} / \mathrm{L}), \mathrm{HsCRP}(15.6 \pm 14.4 \mathrm{mg} / \mathrm{L})$ and IL-6 $(56.1 \pm 28.6 \mathrm{pg} / \mathrm{mL})$ serum levels were significantly higher in patients with PAD than in those WPAD $(3.02 \pm 8.12 \mathrm{ng} /$ $\mathrm{mL}, P^{<} 0.001 ; 2.98 \pm 2.01 \mathrm{pmol} / \mathrm{L}, P<0.001 ; 7.05 \pm 4.4 \mathrm{mg} / \mathrm{L}, P<0.001 ; 37.5 \pm 20.2 \mathrm{pg} / \mathrm{mL}, P<0.001$ respectively). Moreover HMGB-1 $(P<0.001)$, OPG $(P<0.001)$, HsCRP $(P<0.001)$ and IL-6 $(P<0.001)$ serum levels were positively correlated with clinical severity of PAD. HMGB-1 (adjusted OR 12.32; 95\% Cl 3.56-23.54, $P=0.023$ ) and OPG (adjusted OR $3.53 ; 95 \% \mathrm{Cl} 1.54-6.15, P=0.019$ ) resulted independent determinants of PAD in patients with T2D after adjusting for the conventional cardiovascular risk factor and established inflammatory mediators.
\end{abstract}

Conclusions: In T2D patients HMGB-1 and OPG serum levels are higher in patients affected by PAD and independently associated with its occurrence and clinical severity.

Keywords: HMGB-1, OPG, PAD, Type 2 diabetes

\section{Background}

Peripheral arterial disease (PAD) is a clinical manifestation of systemic atherosclerosis affecting ten millions of people worldwide. The frequency of PAD seems to be increasing rapidly in in low-income and middle-income countries, and traditional cardiovascular risk factors of

\footnotetext{
*Correspondence: andrea.flex@unicatt.it

${ }^{6}$ Department of Medicine, A. Gemelli Foundation, Catholic University

School of Medicine, Rome, Italy

Full list of author information is available at the end of the article
}

diabetes, age, smoking, dyslipidemia, and hypertension are likely to be the principal risk factors driving the epidemiological transition [1]. Atherosclerosis is now understood to be an inflammatory disease [2]. Particularly in patients with type 2 diabetes mellitus (T2D) the main mechanisms supposed involved in atherosclerotic disease progression are the decrease of nitric oxide production, the enhancement of oxidative stress, and the impairment of endothelial progenitor cell function [3]. Also in T2D inflammatory circulating molecules as $\mathrm{C}$-reactive protein (HsCRP), tumor necrosis factor-alpha (TNF-alpha), and 
interleukin-6 (IL-6), together with abnormal endothelial expression of intercellular adhesion molecule-1 (ICAM1) and vascular cell adhesion molecule-1 (VCAM-1) support a low-grade chronic state of inflammation and contribute to progression of disease and its complications providing prognostic information on clinical outcomes [4].

Several studies have shown that high mobility group box-1 (HMGB-1), a nuclear protein regulating gene expression, induces an inflammatory response during vascular damage [5]. HMGB-1 is a nuclear protein that has not only a role in the regulation of gene expression but also can activate pro-inflammatory responses after being passively released by damaged and necrotic cells or actively secreted by stimulated conditional innate immune cells such as endothelial cells $[6,7]$. Moreover the release of HMGB-1 induced by HsCRP, one of the most sensitive biomarker of inflammation, induces, amplifies, and extends the inflammatory processes surrounding the atherosclerotic lesions [8]. Further HMGB-1 is not only released in response to pro-inflammatory stimuli, but itself causes the secretion of inflammatory molecules such as IL-6 and TNF-alpha by neutrophils and macrophages [9]. HMGB-1 has been shown be an inflammatory mediator promoting chronic inflammation and neovascularization in diabetes [10]. In addition, an associations between level of HMGB-1 and clinical complications of diabetes has been reported. Particularly a recent study showed that serum HMGB-1 is positively related to HbA1c level and is an independent predictor for coronary artery disease in patients with diabetes [11]. Moreover elevated expression of this protein has been reported in the retinas of diabetic patients and in diabetic nephropathy $[12,13]$. All together those findings suggest that HGMB-1 may contribute to inflammation, endothelial dysfunction and atherosclerosis progression in diabetes mellitus [14]. Also HMGB-1 increases osteoprotegerin (OPG) expression in osteoblasts and is chemotactic to osteoclasts and osteoblasts during endochondral ossification, such as to monocytes and other immune and non-immune cells [15]. OPG is a member of the tumor necrosis factor (TNF) receptor family implied in bone turnover process, osteoporosis and premature vessel calcification [16]. Interestingly recent studies indicate that OPG is an important regulatory molecule in vascular diseases, including cerebral atherosclerosis, and contributes to vessel calcifications in T2D patients, thus suggesting an its possible role in progression of atherosclerotic lesions of other vascular beds such as lower extremity PAD of patients affected by diabetes $[17,18]$. At this regard clinical studies investigating the circulating levels of OPG in patients with PAD have given controversial results [19], showing some of them no serum OPG increase in patient with PAD [20, 21], and others a positive correlation between OPG circulating levels and PAD occurrence [16, 22-24]. However currently the role of OPG and its relationship with chronic inflammatory markers in T2D patients affecting by PAD remains unclear, largely unexplored in experimental and clinical investigations, considering that there are some frequently ignored aspects like polyvascular atherosclerosis which might influence OPG levels [19].

The aims of our current study is to investigate the involvement of serum HMGB-1, OPG, HsCRP, TNFalpha, IL-6 levels on the presence and severity of PAD in patients with $\mathrm{T} 2 \mathrm{D}$.

\section{Methods}

\section{Study population}

Diabetic patients with PAD (PAD) and diabetic controls without PAD (WPAD) were recruited among subjects consecutively admitted to the Department of Internal Medicine of the "A. Gemelli" Catholic University Hospital of Rome, Italy and to the Department of Medicine of the "St. M. Goretti" Hospital, Latina, Italy, from November 1, 2013, to January 30, 2017. Inclusion criteria for diabetic PAD patients were Caucasian race and presence of PAD at Fontaine's stage II, III, or IV. Diagnosis of PAD was performed according to previous criteria established by the Ad Hoc Committee on Reporting Standards of the Society for Vascular Surgery and the International Society for Cardiovascular Surgery $[25,26]$. All PAD patients enrolled in the study $(n=569)$ underwent bilateral highresolution B-mode ultrasonography evaluation (Ecocolor-Doppler Acuson 128XP/10, Acuson, Mountain View, CA, USA, with an $4 \mathrm{MHz}$ transducer) and had an ABI lower than 0.8 and. In according to the Fontaine's staging system, the severity of PAD was defined in stage II when the patients presented claudicatio intermittens, stage III when they presented rest pain, and in stage IV when ischemic trophic lesions of the lower limbs were present [27]. Following the recommendations of the Inter-Society Consensus for the Management of Peripheral Arterial Disease (TASC II), patients with ischemic rest pain, ulcers, or gangrene, attributable to objectively proven $\mathrm{PAD}$, were considered affected by critical limb ischemia (CLI) [28]. Inclusion criteria for diabetic patients WPAD were Caucasian race and absence of PAD evaluated with ankle-brachial-index (ABI) and bilateral high-resolution B-mode ultrasonography. Eight hundred twenty-four diabetic subjects WPAD matched for age and gender were enrolled as controls, with an $\mathrm{ABI} \geq 1$ and normal findings at bilateral high-resolution B-mode ultrasonography evaluation.

Exclusion criteria from the study for whole diabetic population (with and without PAD) were liver disease, 
cancer, serous membrane chamber fluid, hypothyroidism, severe edema and osteoporosis. No one of the patients was taking estrogen supplements, immunosuppressive drugs, thyroxin, glucocorticoids, bisphosphonates and anticoagulants.

The presence of T2D has been confirmed by glycated hemoglobin levels $>5.8 \%$, fasting blood glucose $>126 \mathrm{mg} / \mathrm{dL}$ or by indication for insulin or anti-diabetic medicaments. Hypertension has been defined as systolic blood pressure $>130 \mathrm{mmHg}$, diastolic blood pressure $>85 \mathrm{mmHg}$ or indication to antihypertensive drugs. Hypercholesterolemia has been defined for having serum cholesterol $>220 \mathrm{mg} / \mathrm{dL}$ or use of hypocholesterolemic medications. Nonsmokers were indicated patients that had never smoked or had stopped smoking within $\geq 1$ year before enrollment in the study. All remaining patients were classified as smokers.

Approval for this study was provided by the Ethics Committees of the "A. Gemelli" Catholic University Hospital of Rome, Italy, and "St. M. Goretti" Hospital, Latina, Italy. Informed consent was obtained from enrolled patients.

\section{Biochemical measurements}

For every patient, fast glucose, triglycerides, total cholesterol, low and high-density lipoprotein, white blood cell count have been determined. Blood samples were collected from all individuals involved after an overnight fast. Serum obtained and separated by centrifugation of blood samples was stored at $-80{ }^{\circ} \mathrm{C}$ before every measurement. Serum HMGB-1 level has been determined by a commercially available ELISA kit (HMGB-1 ELISA kit II; Shino-Test Corporation, Tokyo) according to its protocol. The detection limit for HMGB-1 was $0.2 \mathrm{ng} / \mathrm{mL}$ with an inter-assay coefficient of variation $(\mathrm{CV})<10 \%$. HsCRP levels have been determined by using a high-sensitivity ELISA kit (Biocheck Laboratories, Toledo, OH, USA). As a capture antibody we used a monoclonal mouse antihuman OPG antibody and a biotinylated polyclonal goat antihuman OPG antibody (R\&D systems). The intra and inter-assay coefficients of variation were 3.6 and $10.6 \%$, respectively. The sensitivity, defined as the mean $\pm 3 \mathrm{SD}$ of the 0 standard, was calculated to be $0.15 \mathrm{pmol} / \mathrm{mL}$. By using the Quantikine ELISA kit (R\&D Systems, Minneapolis, MN, USA) we have assessed serum IL-6 and TNF-alpha levels. For each patient, the serum levels were measured twice and the results were averaged.

\section{Statistical analysis}

Demographic and clinical data between the groups have been compared using Chi squared and tests. HMGB1, OPG, HsCRP, TNF-alpha and IL-6 serum levels have been compared through Mann-Whitney test. Using a multivariate stepwise logistic regression analysis, two models have been tested. The first one is adjusted for traditional risk factors (all parameters are shown in Table 1), while HMGB-1 and OPG are have been included for testing in the second model. All analyses are performed using the STATA version 11.0 for Windows (Statistics/Data Analysis, Stata Corporation, College Station, TX, USA). Statistical significance has been established at $P<0.05$.

\section{Results}

The socio-demographic and clinical characteristics of diabetic patients with PAD and WPAD are summarized in Table 1. Diabetic PAD patients had higher blood pressure values $(P=0.029)$ and higher $\operatorname{CAD}(P=0.026)$ and were more often smokers $(P=0.023)$. There were no significant differences between groups regarding to median duration of diabetes $(P=0.095)$, fast glucose $(P=0.856)$, glycated hemoglobin $(P=0.763)$, total cholesterol (TC) $(P=0.239)$, HDL-C $(P=0.329)$, LDL-C $(P=0.206)$ and triglyceride $(P=0.913)$. Among 569 PAD patients, 63 diabetic patients (11.1\%) were subjected to only diet, 308 (54.1\%) were taking oral hypoglycemic agents and 198

Table 1 Demographic and clinical data of diabetic subjects with and without PAD

\begin{tabular}{llll}
\hline & $\begin{array}{l}\text { WPAD } \\
(\mathbf{n}=\mathbf{8 2 4})\end{array}$ & $\begin{array}{l}\text { PAD } \\
(\mathbf{n}=\mathbf{5 6 9 )}\end{array}$ & P value \\
\hline Men/female (n) & $490: 334$ & $344: 225$ & $0.243^{\dagger}$ \\
Age (years \pm SD) & $71.3 \pm 4.4$ & $70.7 \pm 4.3$ & $0.647^{*}$ \\
Smoking (current) (\%) & $181(22.0)$ & $210(36.9)$ & $0.023^{\dagger}$ \\
Hypertension (\%) & $335(40.7)$ & $355(62.4)$ & $0.029^{\dagger}$ \\
CAD (\%) & $275(33.4)$ & $297(52.2)$ & $0.026^{\dagger}$ \\
Diabetes duration (years \pm SD) & $12.1 \pm 4.1$ & $12.7 \pm 4.9$ & $0.095^{*}$ \\
Total cholesterol (mmol/L) & $4.97(1.21)$ & $4.87(1.15)$ & $0.239^{*}$ \\
HDL-C (mmol/L) & $1.21(1.04)$ & $1.23(1.02)$ & $0.329^{*}$ \\
LDL-C (mmol/L) & $2.96(1.02)$ & $2.87(0.93)$ & $0.206^{*}$ \\
Triglyceride (mmol/L) & $2.05(1.54)$ & $1.87(0.98)$ & $0.913^{*}$ \\
Fast glucose (mmol/L) & $6.89(1.92)$ & $7.01(2.65)^{\mathrm{a}}$ & $0.856^{*}$ \\
Glycated hemoglobin (\%) & $7.37(1.21)$ & $7.24(1.14)$ & $0.763^{*}$ \\
Treatment & & & \\
Diet only (\%) & $95(11.5)$ & $63(11.1)$ & $0.658^{\dagger}$ \\
Oral agents (\%) & $452(54.9)$ & $308(54.1)$ & $0.341^{\dagger}$ \\
Insulin therapy (\%) & $277(33.6)$ & $198(34.8)$ & $0.290^{\dagger}$ \\
PAD & & & \\
1-Fontaine's II (\%) & & $281(49.4)$ & \\
2-Fontaine's III (\%) & & $163(28.6)$ & \\
2-Fontaine's IV (\%) & & & \\
\hline
\end{tabular}

Data are number (\%) and standard deviation (SD)

$C A D$ coronary artery disease, $H D L-C$ high-density lipoprotein cholesterol, $L D L-C$ low-density lipoprotein cholesterol

* Statistical test performed with Student's t test

+ Chi square test for categorical values 
(34.8\%) were prescribed insulin. According to the Fontaine's classification 281 patients were defined as stage II, 163 as stage III and 125 as stage IV.

The diabetic PAD patients group had higher HMGB-1 $(7.89 \pm 15.23 \mathrm{ng} / \mathrm{mL})$, OPG $(6.54 \pm 7.76 \mathrm{pmol} / \mathrm{L}), \mathrm{HsCRP}$ $(15.6 \pm 14.4 \mathrm{mg} / \mathrm{L})$ and IL-6 $(56.1 \pm 28.6 \mathrm{pg} / \mathrm{mL}) \mathrm{com}-$ pared to WPAD group $(3.02 \pm 8.12 \mathrm{ng} / \mathrm{mL}, P<0.001$; $2.98 \pm 2.01 \mathrm{pmol} / \mathrm{L}, P<0.001 ; 7.05 \pm 4.4 \mathrm{mg} / \mathrm{L}, P<0.001$; $37.5 \pm 20.2 \mathrm{pg} / \mathrm{mL}, P<0.001$ respectively) (Fig. 1 ). No differences in serum TNF-alpha levels were detected $(P<0.213)$.

When diabetic PAD patients were divided into two clinical categories, the first one consisting in patients affected by stable PAD (stage II, $\mathrm{n}=281$ ) and the second consisting in patients affected by CLI (stage III and $\mathrm{IV}, \mathrm{n}=288$ ), interestingly current smoking, CAD, diabetes duration, TC and LDL-C were significantly and independently associated with CLI (Table 2). Moreover serum levels of pro-inflammatory cytokines were significantly higher in diabetic PAD patients having CLI than in those with stable PAD (HMGB-1 $8.35 \pm 12.72 \mathrm{ng} / \mathrm{mL}$ vs $4.53 \pm 7.65 \mathrm{ng} / \mathrm{mL}, P<0.001$; OPG $7.64 \pm 9.29 \mathrm{pmol} / \mathrm{L}$ vs $3.24 \pm 2.56 \mathrm{pmol} / \mathrm{L}, P<0.001 ; \mathrm{HsCRP} 18.1 \pm 15.9 \mathrm{mg} / \mathrm{L}$ vs $9.3 \pm 5.1 \mathrm{mg} / \mathrm{L}, P<0.001 ; \mathrm{IL}-662.1 \pm 29.4 \mathrm{pg} / \mathrm{mL}$ vs $41.5 \pm 18.7 \mathrm{pg} / \mathrm{mL}, P<0.001$ ) (Fig. 2).

The multivariate logistic regression analysis showed that in the model 1 , after adjustments for cardiovascular risk factors and inflammatory cytokines, showed that smoking, hypertension, hyperlipidemia, TC, HDL$\mathrm{C}$, LDL-C, HsCRP and IL-6 were independent determinants for PAD occurrence in patients with T2D. When HMGB-1 and OPG were included in the multivariate analysis (model 2), HMGB-1 (adjusted OR 12.32; 95\% CI 3.56-23.54, $P=0.023$ ) and OPG (adjusted OR 3.53; 95\% CI 1.54-6.15, $P=0.019$ ) are resulted independently associated with PAD in T2D patients and most of the traditional cardiovascular risk factors shown in model 1 remained determinants of PAD even in model 2 (Table 3 ).

\section{Discussion}

Cross-talk between HMGB-1 and inflammatory molecules

The present study has demonstrated in a large population of T2D patients that serum HMGB-1 levels are significantly increased in PAD patients and correlated with clinical severity. Particularly we found that the HMGB-1 serum levels are statistically significant higher in T2D patients with PAD than in diabetic control WPAD $(P<0.001)$. Our observations are consistent with the study of Oozawa and collaborators, conducted in smaller population where few diabetic patients were compared to healthy controls, instead of T2D patients [29]. Our choice to investigate only diabetic patients has been suggested

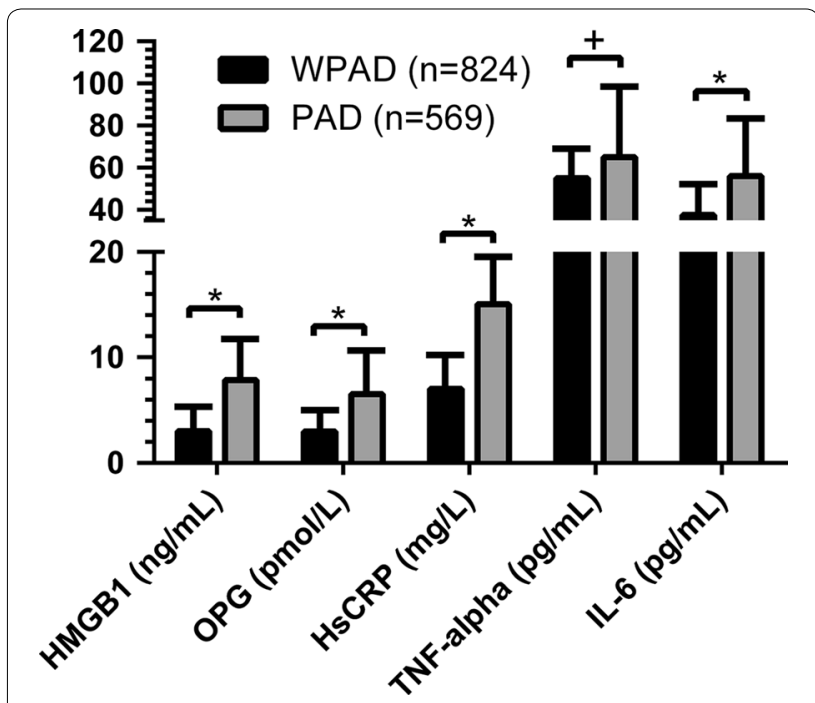

Fig. 1 HMGB-1, OPG, HsCRP, TNF-alpha and IL-6 serum levels in diabetic patients with (PAD) and without PAD (WPAD). HMGB-1 highmobility group box 1, OPG osteoprotegerin, HsCRP high-sensitivity C-reactive protein, TNF-alpha tumor necrosis factor-alpha, IL-6 Interleukin-6. Statistical test performed with Student's t test. Data are shown as serum levels \pm standard deviation. ${ }^{*} P<0.001,{ }^{+}$N.S

by the evidence that diabetes is one of the strongest predictor for critical limb ischemia occurrence [30].

Furthermore HMGB-1 serum levels increased according to the Fontaine's stage. In fact when diabetic PAD patients were divided into two clinical categories, consisting in patients affected by stable PAD and in patients affected by CLI, HMGB-1 serum levels were significantly higher in patients affected by CLI than stable PAD $(P<0.001)$.

In addition the present study confirmed our previous data showing that OPG, HsCRP and IL-6 serum levels are associated with $\operatorname{PAD}(P<0.001, P<0.001$ and $P<0.001$ respectively; Fig. 1$)$ and gradually increase according to clinical severity of disease (Fig. 2). The relationship persists significant also after adjustment for potential confounding variables such as age, smoking status, hypertension, serum lipid profile, glycaemic control, and chronic inflammation. A multivariate logistic regression analysis demonstrate that both HMGB-1 and OPG remain independently associated with CLI in diabetic patients (model 2) and most of traditional risk factors in model 1 are determinants of CLI also in model 2 (Table 3).

Our data are in agreement with previous reporting suggesting a cross-talk among HMGB-1 and inflammatory molecules, including CRP. Specifically Kawahara and coworkers demonstrated that, through the p38MAPK pathway, CRP induces the production of HMGB-1 in a dose-dependently way [8]. Moreover HMGB-1 
Table 2 Demographic and clinical data of diabetic PAD patients with Fontaine's II and CLI

\begin{tabular}{|c|c|c|c|c|c|}
\hline & $\begin{array}{l}\text { Fontaine's II } \\
(281)\end{array}$ & $\begin{array}{l}\text { CLI } \\
(288)\end{array}$ & P value & OR $(95 \% \mathrm{Cl})^{\S}$ & P value \\
\hline Men/female (n) & $166: 115$ & $176: 112$ & $0.275^{+}$ & $0.91(0.4-2.1)$ & 0.823 \\
\hline Age (years $\pm S D$ ) & $71.9 \pm 3.4$ & $72.7 \pm 4.4$ & $0.431^{*}$ & $1.00(0.9-1.00)$ & 0.476 \\
\hline Smoking (current) (\%) & $56(19.9)$ & $154(53.4)$ & $0.001^{\dagger}$ & $3.43(2.15-3.65)$ & 0.001 \\
\hline Hypertension (\%) & $173(61.6)$ & $182(63.2)$ & $0.143^{\dagger}$ & $0.89(0.62-1.04)$ & 0.327 \\
\hline CAD (\%) & $102(36.3)$ & $195(67.7)$ & $0.001^{\dagger}$ & $3.74(2.49-4.02)$ & 0.001 \\
\hline Diabetes duration (years \pm SD) & $9.3 \pm 3.1$ & $15.7 \pm 5.1$ & $0.001^{\dagger}$ & $4.37(3.07-5.12)$ & 0.001 \\
\hline Total cholesterol (mmol/L) & $3.65(1.12)$ & $5.68(1.83)$ & $0.001^{\dagger}$ & $2.05(1.54-3.02)$ & 0.001 \\
\hline $\mathrm{HDL}-\mathrm{C}(\mathrm{mmol} / \mathrm{L})$ & $1.15(1.01)$ & $1.31(1.09)$ & $0.247^{\dagger}$ & $0.85(0.69-1.01)$ & 0.296 \\
\hline LDL-C (mmol/L) & $1.95(0.87)$ & $3.25(1.43)$ & $0.001^{\dagger}$ & $2.69(1.32-4.12)$ & 0.001 \\
\hline Triglyceride (mmol/L) & $1.95(1.45)$ & $1.93(1.06)$ & $0.473^{\dagger}$ & $1.32(0.71-1.58)$ & 0.456 \\
\hline Fast glucose $(\mathrm{mmol} / \mathrm{L})$ & $6.78(1.84)$ & $6.97(2.46)$ & $0.945^{\dagger}$ & $1.02(0.56-1.34)$ & 1.001 \\
\hline Glycated hemoglobin (\%) & $7.25(1.16)$ & $7.33(1.32)$ & $0.854^{\dagger}$ & $1.00(0.43-1.15)$ & 0.765 \\
\hline
\end{tabular}

Data are number (\%) and standard deviation (SD)

$C A D$ coronary artery disease, $H D L-C$ high-density lipoprotein cholesterol, $L D L-C$ low-density lipoprotein cholesterol

* Statistical test performed with Student's t test

+ Chi square test for categorical values

$\S$ Logistic regression analysis. OR odds ratios, $95 \%$ Cl 95\% confidence intervals

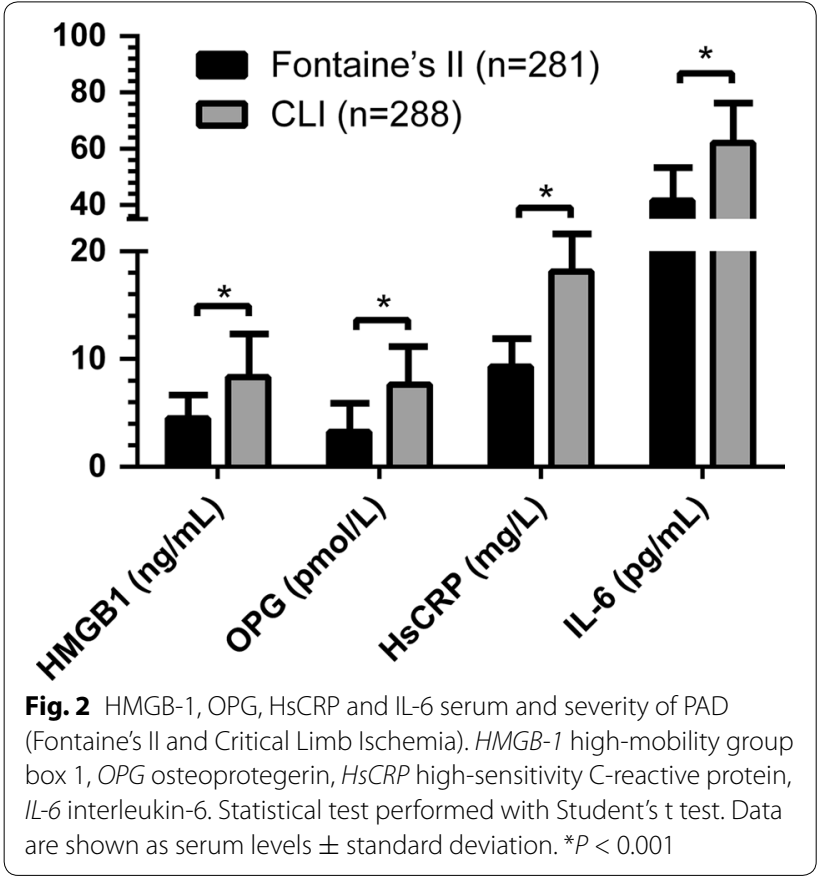

up-regulates pro-inflammatory cytokines expression [31, 32 , suggesting that this way contributes to the inflammatory process and to atherosclerotic lesion development $[33,34]$. The role of chronic inflammation in the development of PAD and of its complications has been extensively investigated in the past. Malmstedt reported the role of the receptor for advanced glycation end
Table 3 Multivariable stepwise logistic regression model for presence of PAD

\begin{tabular}{lcr}
\hline & Variable OR (95\% Cl) & P value \\
\hline Model 1 & & \\
Age & $1.02(1.01-1.19)$ & 0.146 \\
Smoking & $36.71(4.54-179.31)$ & 0.001 \\
Hypertension & $24.91(5.56-89.65)$ & $<0.001$ \\
Hyperlipidemia & $12.54(2.45-28.34)$ & 0.022 \\
TC & $1.56(1.06-1.94)$ & 0.034 \\
HDL-C & $0.02(0.01-0.22)$ & 0.001 \\
LDL-C & $9.43(1.65-74.34)$ & 0.066 \\
hsCRP & $35.32(7.45-129.22)$ & $<0.001$ \\
IL-6 & $6.01(2.02-16.02)$ & 0.012 \\
Model 2 & & \\
Sex & $0.15(0.02-0.94)$ & 0.097 \\
Age & $1.56(1.15-1.78)$ & 0.164 \\
Smoking & $66.43(4.21-654.01)$ & 0.012 \\
Hypertension & $41.12(6.24-189.54)$ & $<0.001$ \\
Hyperlipidemia & $8.57(1.57-49.24)$ & 0.017 \\
TC & $0.05(0.01-0.43)$ & 0.012 \\
HDL-C & $0.01(0.00-0.24)$ & 0.001 \\
LDL-C & $13.86(1.34-153.27)$ & 0.019 \\
hsCRP & $65.89(8.11-436.53)$ & $<0.001$ \\
IL-6 & $7.87(2.47-18.04)$ & 0.008 \\
HMGB-1 & $12.32(3.56-23.54)$ & 0.023 \\
OPG & $3.53(1.54-6.15)$ & 0.019 \\
\hline Mode 1:adusted for tadtion & & \\
\hline & &
\end{tabular}

Model 1: adjusted for traditional cardiovascular risk factors and established inflammatory cytokines; Model 2: adjusted for the risk factors in model 1 plus HMGB-1 and OPG 
products (RAGE), showing that higher circulating levels of an endogenous ligand for RAGE, the pro-inflammatory protein S100A12, was associated with increased risk for amputation or death and with earlier development of PAD [35]. Several circulating inflammatory biomarkers have been suggested to predict occurrence (i.e. Rho-kinase activity, human cartilage glycoprotein-39, TWEAK, PON-3, B2M, NO, NOX-2, TGF- $\beta 1$, TSP-1, VEGF) and/or the severity of PAD (i.e. sVCAM-1, MPO, NT-proBNP, VEGF, VEGF-A isoforms and MMPs). Anyway their validity as reliable clinical markers is still debated [36].

Two sources have been proposed to increase HMGB-1 circulating levels, the local HMGB-1 release promoted by damaged immune cells such as monocytes, macrophages, endothelial cells cytokine-triggered, or the secretion from vascular smooth muscle cells (VSMCs) in atherosclerotic lesions [5, 37]. Moreover VSMCs may be both source and target of HMGB-1 having been shown VSMCs proliferation following HMGB-1 self-secreted by them. This mechanism could explain our observation that HMGB-1 serum levels strongly correlate with PAD severity. In fact, as atherosclerosis goes over, more macrophages releasing HMGB-1 are recruited and induce proliferation and migration of VSMCs that in turn increase their self-secretion of HMGB-1 stimulating further their proliferation. This mechanism self-perpetuating can contribute to progression of atherosclerotic lesions [33]. Moreover HMGB-1 mRNA expression could be strongly up-regulated by inflammatory cytokines such as TNFalpha [33]. In our study we have confirmed that serum levels of TNF- $\alpha$, as well IL- 6 and HsCRP, are significantly increased in diabetic patients with concomitant PAD $[38,39]$. Similarly in animal studies HMGB-1 has been shown play an important role in atherosclerotic process exerting pro-atherogenic effects through the modulation of pro-inflammatory mediators, macrophage migration, and accumulating smooth muscle and immune cells. HMGB-1 neutralization also reduces diet-induced atherosclerosis in apolipoprotein E-deficient mice [40]. Moreover high HMGB-1 serum levels have been reported be associated with CAD in patients with and without T2D and they were gradually correlated with the severity of coronary artery stenosis $[41,42]$.

\section{OPG and its role in endothelial dysfunction}

HMGB-1 is a bone-active cytokine and on multiple murine bone cells culture recombinant protein (rHMGB1) enhanced the RANKL/OPG steady state mRNA ratio and augmented the release of TNF-alpha and IL- 6 in osteoblastogenic bone marrow stromal cell (BMSC) [15]. In our study we also measured circulating levels of OPG establishing a positive correlation between serum OPG levels and the occurrence of PAD in diabetic patients (Fig. 1). Moreover OPG has resulted a significant predictor of disease severity (Fig. 2).

The association between OPG and atherosclerosis in CAD is quite well studied. OPG has been reported an independent risk factor for development and progression of atherosclerosis in patients with CAD [43]. Also OPG predicted early carotid atherosclerosis in patients with CAD [44]. In our study, as shown in Table 1, CAD occurrence is similar between the two groups $(P=0.294)$, thus it is to be ruled out it as a possible confounder. Studies investigating the role of OPG in PAD have done contrasting and uncertain results. While some of them did not find any serum OPG level increase in patient with $\operatorname{PAD}[19,20]$, others showed a positive correlation between circulating OPG and severity of PAD [18] or reported OPG as an independent predictor of PAD [33]. More recently two studies investigated the association between OPG and PAD in T2D patients $[45,46]$ and demonstrated that OPG concentrations are significantly increased in T2D patients having PAD in comparison with T2D without PAD. However they have focused on a smaller and younger population of patients, and no data were available regarding $\mathrm{CAD}$ occurrence as in our report. A recent our report showed a significant positive association between OPG serum levels and occurrence and severity of PAD in a population of T2D [23]. However in this study, patients affected by PAD also had a significantly higher occurrence of CAD compared to diabetic patients without PAD, so it could not be ruled out as possible bias to investigations. Of interest, we also reported for the first time that fibroblast growth factor 23 (FGF23) is a predictor of PAD occurrence and severity, moving from a previous report of our group [47] in which we suggested the association between FGF23 and OPG in patients with unstable carotid plaques, thus underlying the role of the two molecules in the development of atherosclerosis owing to their contribute to vascular calcification. To corroborate the involvement of FGFs family members in the early stage of atherosclerosis, Zhang's group [48] observed that circulating FGF21, an emerging metabolite regulating glucose and lipid metabolism, is directly associated with lower extremity atherosclerosis disease. They also found an association between serum FGF21 levels and carotid intima thickness in the female group, accounting maybe for a gender-specific effect. All together these studies took in account the endothelial dysfunction, an early and important trigger of atherogenesis, as mechanism responsible for PAD development and worsening. In this direction an interesting significant association of high OPG was found with the non-0 blood groups in PAD patients, considering that non-0 blood group subjects have a well-established higher risk 
of developing thrombotic episode of venous or arterial origin [49].

Whether OPG plays a causal role in mediating or protecting against vascular injury is presently unclear. An atheroprotective effect of OPG could be related to its anti-calcification function or due to its action as a decoy receptor for the receptor activator of nuclear factor-B ligand (RANK-L) and the TNF-related apoptosis inducing ligand (TRAIL) by which it blocks their subsequent pro-inflammatory and pro-apoptotic effects $[50,51]$. In particular OPG has been identified as an in vitro survival factor for endothelial cells [52]. On the other hand recent evidence supports a pro-atherosclerotic role for OPG including its capacity to enhance the expression of endothelial cell adhesion molecules promoting infiltration of leukocytes and monocytic cells [53]. However, there are some frequently ignored aspects like polyvascular atherosclerosis which might influence OPG levels [19]. Furthermore, OPG might contribute to endothelial dysfunction by reducing the nitric oxide synthase protective pathway by blocking RANK-L [54]. A longitudinal prospective study is needed to clarify the causal relationship among HMGB-1, OPG and PAD.

\section{Limitations}

There are some limitations in the present study. First, we developed a case-control study, thus survival and enrollment bias should be considered. Second, we collected data from an European cohort having other cardiovascular diseases. Also, comorbidities might represent confounding factors and our findings are not generalizable to other age groups or ethnicities. So our observations need to be confirmed in larger populations and different ethnic groups. Finally the influence of other pro-inflammatory molecules such as myeloperoxidase, soluble adhesion molecules, sCD40 and matrix metalloproteinases did not evaluate in this study.

\section{Conclusions}

The present study demonstrated that HMGB-1 and OPG serum levels are statistically and independently associated with occurrence and clinical severity of PAD in an Italian population affected by T2D. The understanding of pathophysiological mechanisms and of molecular pathways responsible for HMGB-1 and OPG involvement in atherosclerosis disease may provide us new therapeutic weapons to manage diabetic complications and morbidities. Furthermore the measurement of these two serum markers could be useful as diagnostic and prognostic markers of PAD in diabetic patients.

\section{Abbreviations}

ABI: ankle-brachial-index; BMSC: bone marrow stromal cell; B2M: beta 2 microglobulin; CAD: coronary artery disease; CLI: critical limb ischemia; FGF21: fibroblast growth factor 21; FGF23: fibroblast growth factor 23; HDL-C: highdensity lipoprotein cholesterol; HMGB-1: high mobility group box-1; HsCRP: high sensitive C-reactive protein; ICAM-1: intercellular adhesion molecule-1; IL6: interleukin-6; LDL-C: low-density lipoprotein cholesterol; MMPs: matrix metalloproteinases; MPO: myeloperoxidase; NO: nitric oxide; NOX-2: nicotinamide adenine dinucleotide phosphate oxidase-2; NT-proBNP: N-terminal pro-brain natriuretic peptide; OPG: osteoprotegerin; OR: odds ratio; PAD: peripheral arterial disease; PON-3: paraoxonase-3; RAGE: receptor for advanced glycation end products; rHMGB-1: recombinant protein HMGB-1; SD: standard deviation; sVCAM-1: soluble intercellular adhesion molecule 1; TC: total cholesterol; TGF$\beta 1$ : transforming growth factor- $\beta 1$; TNF-alpha: tumor necrosis factor-alpha; TSP-1: thrombospondin-1; T2D: type 2 diabetes; TWEAK: tumor necrosis factorrelated weak inducer of apoptosis; VEGF: vascular endothelial growth factor; WPAD: without peripheral artery disease.

\section{Authors' contributions}

$\mathrm{SG}, \mathrm{GT}, \mathrm{FB}, \mathrm{RF}$ and $\mathrm{AF}$ contributed to the conception and design of the research; LM, SG, GS and DP contributed to the acquisition of data; FB, FA and GS contributed to the analysis and interpretation of data; LM, AF and RF contributed to drafting the article. All authors have revised the manuscript critically for important intellectual content. All authors read and approved the final manuscript.

\section{Author details}

${ }^{1}$ Department of Gerontology and Geriatrics, A. Gemelli Foundation, Catholic University of the Sacred Heart, School of Medicine, Rome, Italy. ${ }^{2}$ Department of Vascular Surgery, A. Gemelli Foundation, Catholic University of the Sacred Heart, School of Medicine, Rome, Italy. ${ }^{3}$ Rheumatology and Affine Sciences Institute, A. Gemelli Foundation, Catholic University of the Sacred Heart, School of Medicine, Rome, Italy. ${ }^{4}$ Laboratory of Vascular Biology and Genetics, Catholic University School of Medicine, Rome, Italy. ${ }^{5}$ Vascular Medicine and Atherothrombosis Laboratory, Department of Experimental Medicine, Sapienza University of Rome, Polo Pontino, Italy. ${ }^{6}$ Department of Medicine, A. Gemelli Foundation, Catholic University School of Medicine, Rome, Italy.

\section{Acknowledgements \\ None.}

Competing interests

The authors declare that they have no competing interests.

\section{Availability of data and materials}

All data generated or analyzed during this study are included in this published article.

\section{Consent for publication}

This manuscript does not contain any data from any individual person. If the manuscript is accepted, we approve it for publication in Cardiovascular Diabetology.

\section{Ethics approval and consent to participate}

The study was approved by the local ethics committee, in accordance with the Helsinki Declaration, and all patients gave their written informed consent.

Funding information

Non applicable.

\section{Publisher's Note}

Springer Nature remains neutral with regard to jurisdictional claims in published maps and institutional affiliations.

Received: 5 June 2017 Accepted: 28 July 2017

Published online: 08 August 2017 


\section{References}

1. Hirsch AT, Criqui MH, Treat-Jacobson D, Regensteiner JG, Creager MA, Olin JW, Krook SH, Hunninghake DB, Comerota AJ, Walsh ME, McDermott MM, Hiatt WR. Peripheral arterial disease detection, awareness, and treatment in primary care. JAMA. 2001;286(11):1317-24.

2. Ross R. Atherosclerosis is an inflammatory disease. N Engl J Med. 1999:340(2):115-26.

3. Tousoulis DL, Kampoli AM, Stefanadis C. Diabetes mellitus and vascular endothelial dysfunction: current perspectives. Curr Vasc Pharmacol. 2012;10(1):19-32

4. Tousoulis DL, Papageorgiou N, Androulakis E, Siasos G, Latsios G, Tentolouris K, Stefanadis C. Diabetes mellitus-associated vascular impairment: novel circulating biomarkers and therapeutic approaches. J Am Coll Cardiol. 2013;62(8):667-76

5. Scaffidi P, Misteli T, Bianchi ME. Release of chromatin protein HMGB1 by necrotic cells triggers inflammation. Nature. 2002;418:191-5.

6. Fiuza C, Bustin M, Talwar S, Tropea M, Gerstenberger E, Shelhamer JH, Suffredini AF. Inflammation-promoting activity of HMGB1 on human microvascular endothelial cells. Blood. 2003;101(7):2652-60.

7. Mai J, Virtue A, Shen J, Wang H, Yang XF. An evolving new paradigm: endothelial cells-conditional innate immune cells. J Hematol Oncol. 2013:22(6):61

8. Kawahara K, Biswas KK, Unoshima M, Ito T, Kikuchi K, Morimoto Y, Iwata M, Tancharoen S, Oyama Y, Takenouchi K, et al. C-reactive protein induces high mobility group box-1 protein release through activation of p38MAPK in macrophage RAW264 7 cells. Cardiovasc Pathol. 2008:17(3):129-38.

9. Erlandsson Harris $\mathrm{H}$, Andersson U. Mini-review: the nuclear protein HMGB-1 as a proinflammatory mediator. Eur J Immunol. 2004;34(6):1503-12.

10. Nogueira-Machado JA, Volpe CMDO, Veloso CA, Chaves MM. HMGB1, TLR and RAGE: a functional tripod that leads to diabetic inflammation. Expert Opin Ther Targets. 2011;15(8):1023-35.

11. Zhao Z, Wang Y, Tang K, Xu Y. Increased serum HMGB1 related with $\mathrm{HbA} 1 \mathrm{C}$ in coronary artery disease in type 2 diabetes mellitus. Int J Cardiol. 2013;168(2):1559-60.

12. Pachydaki SI, Tari SR, Lee SE, Ma W, Tseng JJ, Sosunov AA, Cataldergirmen G, Scarmeas N, Caspersen C, Chang S, et al. Upregulation of RAGE and its ligands in proliferative retinal disease. Exp Eye Res. 2006;82(5):807-15.

13. Kim J, Sohn E, Kim C-S, Jo K, Kim JS. The role of high mobility group box-1 protein in the development of diabetic nephropathy. Am J Nephrol. 2011;33(6):524-9.

14. Skrha J Jr, Kalousova M, Svarcová J, Muravska A, Kvasnička J, Landová L, Zima T, Slrha J. Relationship of soluble RAGE and RAGE ligands HMGB1 and EN-RAGE to endothelial dysfunction in type 1 and type 2 diabetes mellitus. Exp Clin Endocrinol Diabetes. 2012;120(05):277-81.

15. Yang J, Shah R, Robling AG, Templeton E, Yang H, Tracey KJ, Bidwell JP. HMGB1 is a bone-active cytokine. J Cell Physiol. 2008;214(3):730-9.

16. Ziegler S, Kudlacek S, Luger A, Minar E. Osteoprotegerin plasma concentrations correlate with severity of peripheral artery disease. Atherosclerosis. 2005:182(1):175-80.

17. Kim J, Song TJ, Yang SH, Lee OH, Nam HS, Kim YD, Kim EH, Lee HS, Nam $\mathrm{CM}, \mathrm{HeO} \mathrm{JH}$. Plasma osteoprotegerin levels increase with the severity of cerebral artery atherosclerosis. Clin Biochem. 2013;46(12):1036-40.

18. Harper E, Forde H, Davenport C, Rochfort KD, Smith D, Cummins PM. Vascular calcification in type-2 diabetes and cardiovascular disease: integrative roles for OPG, RANK, TRAIL. Vasc Pharmacol. 2016;82:30-40.

19. Kapetanios D, Karkos C, Giagtzidis I, Papazoglou K, Kiroplastis K, Spyridis C. Vascular calcification biomarkers and peripheral arterial disease. Int Angiol. 2016;35(5):455-9.

20. Koshikawa M, Aizawa K, Kasai H, Izawa A, Tomita T, Kuzamaki S, Tsutsui H, Koyama J, Shimodaira S, Takahashi M, et al. Elevated osteopontin levels in patients with peripheral arterial disease. Angiology. 2009;60(1):42-5

21. Pennisi P, Signorelli SS, Riccobene S, Celotta G, Di Pino L, La Malfa T, Fiore CE. Low bone density and abnormal bone turnover in patients with atherosclerosis of peripheral vessels. Osteoporos Int. 2004;15(5):389-95.

22. Knudseb ST, Foss CH, Poulsen PL, Andersen NH, Mogensen CE, Rasmussen LM. Increased plasma concentrations of osteoprotegerin in type 2 diabetic patients with microvascular complications. Eur J Endocrinol. 2003:149(1):39-42.
23. Xiang GD, Xu L, Zhao LS, Yue L, Hou J. The relationship between plasma osteoprotegerin and endothelium-dependent arterial dilation in type 2 diabetes. Diabetes. 2006:55(7):2126-31.

24. Biscetti F, Straface G, Pitocco D, Angelini F, Tinelli G, Landolfi R, Flex A. Fibroblast growth factor 23 serum level in type 2 diabetic italian subjects with peripheral arterial disease and critical limb ischemia. Eur Rev Med Pharmacol Sci. 2016;20(19):4048-54.

25. Tendera M, Aboyans V, Bartelink ML, Baumgartner I, Clément D, Collet JP, Cremonesi A, De Carlo M, Erbel R, Fowkes FG, et al. ESC guidelines on the diagnosis and treatment of peripheral artery diseases: document covering atherosclerotic disease of extracranial carotid and vertebral, mesenteric, renal, upper and lower extremity arteries: the task force on the diagnosis and treatment of peripheral artery diseases of the european society of cardiology (ESC). Eur Heart J. 2011;32(22):2851-906.

26. Gerhard-Herman MD, Gornik HL, Barrett C, Barshes NR, Corriere MA, Drachman DE, Fleisher LA, Fowkes FG, Hamburg NM, Kinlay S, et al. 2016 AHA/ACC guideline on the management of patients with lower extremity peripheral artery disease: a report of the American College of Cardiology/American Heart Association Task Force on Clinical Practice Guidelines. J Am Coll Cardiol. 2017:69(11):e71-126.

27. Rutherford RB, Flanigan DP, Gupta SK, The Ad Hoc Committee on Reporting Standards SVS/ISCVS. Suggested standards for reports dealing with lower extremity ischaemia. J Vasc Surg. 1986;4(1):80-94.

28. Norgren L, Hiatt WR, Dormandy JA, Nehler MR, Harris KA, Fowkes FG, TASC II Working Group. Inter-society consensus for the management of peripheral arterial disease (TASC II). J Vasc Surg. 2007:45:S5-67.

29. Oozawa S, Sano S, Nishibori M. Usefulness of high mobility group box 1 protein as a plasma biomarker in patient with peripheral artery disease. Acta Med Okayama. 2014;68(3):157-62.

30. Wyss TR, Adam L, Haynes AG, Kucher N, Silbernagel G, Do DD, Schmidli J, Baumgartner I. Impact of cardiovascular risk factors on severity of peripheral artery disease. Atherosclerosis. 2015;242(1):97-101.

31. Andersson U, Wang H, Palmblad K, Aveberger AC, Bloom O, ErlandssonHarris H, Janson A, Kokkola R, Zhang M, Yang H, Tracey KJ. High mobility group 1 protein (HMG-1) stimulates proinflammatory cytokine synthesis in human monocytes. J Exp Med. 2000;192(4):565-70.

32. Wang $\mathrm{H}$, Bloom $\mathrm{O}$, Zhang $M$, Vishnubhakat JM, Ombrellino M, Che J, Frazier A, Yang H, Ivanova S, Borovikova L, et al. HMG-1 as a late mediator of endotoxin lethality in mice. Science. 1999;285(5425):248-51.

33. Kalinina N, Agrotis A, Antropova Y, DiVitto G, Kanellakis P, Kostolias G, Ilyinskaya O, Tararak E, Bobik A. Increased expression of the DNA binding cytokine HMGB1 in human atherosclerotic lesions: role of activated macrophages and cytokines. Arterioscler Thromb Vasc Biol. 2004:24(12):2320-5.

34. Li W, Sama AE, Wang H. Role of HMGB1 in cardiovascular diseases. Curr Opin Pharmacol. 2006:6(2):130-5.

35. Malmstedt J, Kärvestedt L, Swedenborg J, Brismar K. The receptor for advanced glycation end products and risk of peripheral arterial disease, amputation or death in type 2 diabetes: a population-based cohort study. Cardiovasc Diabetol. 2015;14:93.

36. Krishna SM, Moxon JV, Golledge J. A review of the pathophysiology and potential biomarkers for peripheral artery disease. Int J Mol Sci. 2015:16(5):11294-322.

37. Porto A, Palumbo R, Pieroni M, Aprigliano G, Chiesa R, Sanvito F, Maseri A, Bianchi ME. Smooth muscle cells in human atherosclerotic plaques secrete and proliferate in response to high mobility group box 1 protein. FASEB J. 2006:20(14):2565-6.

38. Brevetti G, Piscione F, Silvestro A, Galasso G, Di Donato A, Oliva G, Scopacasa F, Chiariello M. Increased inflammatory status and higher prevalence of three-vessel coronary artery disease in patients with concomitant coronary and peripheral atherosclerosis. Thromb Haemost. 2003:89(6):1058-63

39. Unlü Y, Karapolat S, Karaca Y, Kiziltunç A. Comparison of levels of inflammatory markers and hemostatic factors in the patients with and without peripheral arterial disease. Thromb Res. 2006;117(4):357-64.

40. Kanellakis P, Agrotis A, Kyaw TS, Koulis C, Ahrens I, Mori S, Takahashi HK, Liu K, Peter K, Nishibori M, et al. High-mobility group box protein 1 neutralization reduces development of diet-induced atherosclerosis in apolipoprotein e-deficient mice. Arterioscler Thromb Vasc Biol. 2011:31(2):313-9. 
41. Yan XX, Lu L, Peng WH, Wang LJ, Zhang Q, Zhang RY, Chen QJ, Shen WF. Increased serum HMGB1 level is associated with coronary artery disease in non diabetic and type 2 diabetic patients. Atherosclerosis. 2009;205(2):544-8.

42. Hu X, Jiang H, Bai Q, Zhou X, Xu C, Lu Z, Cui B, Wen H. Increased serum HMGB1 is related to the severity of coronary artery stenosis. Clin Chim Acta. 2009;406(1-2):139-42.

43. Kiechl S, Schett G, Wenning G, Redlich K, Oberhollenzer M, Mayr A, Santer P, Smolen J, Poewe W, Willeit J. Osteoprotegerin is a risk factor for progressive atherosclerosis and cardiovascular disease. Circulation. 2004;109(18):2175-80.

44. Morisawa T, Nakagomi A, Kohashi K, Kosugi M, Kusama Y, Atarashi H, Shimizu W. Osteoprotegerin is associated with endothelial function and predicts early carotid atherosclerosis in patients with coronary artery disease. Int Heart J. 2015;56(6):605-12.

45. Esteghamati A, Aflatoonian M, Rad MV, Mazaheri T, Mousavizadeh M, Nakhjavani M, Noshad S. Association of osteoprotegerin with peripheral artery disease in patients with type 2 diabetes. Arch Cardiovasc Dis. 2015;108(8-9):412-9.

46. Niu Y, Zhang W, Yang Z, Li X, Wen J, Wang S, Zhang H, Wang X, Zhou $H$, Fang W, et al. Association of plasma osteoprotegerin levels with the severity of lower extremity arterial disease in patients with type 2 diabetes. BMC Cardiovasc Disord. 2015;15:86.

47. Biscetti F, Straface G, Porreca CF, Bertoletti G, Vincenzoni C, Snider F, Stigliano E, Arena V, Angelini F, Pecorini G, et al. Increased FGF23 serum level is associated with unstable carotid plaque in type 2 diabetic subjects with internal carotid stenosis. Cardiovasc Diabetol. 2015;14:139.
48. Zhang X, Hu Y, Zeng H, Li L, Zhao J, Zhao J, Liu F, Bao Y, Jia W. Serum fibroblast growth factor 21 levels is associated with lower extremity atherosclerotic disease in Chinese female diabetic patients. Cardiovasc Diabetol. 2015;14:32.

49. Nagy EE, Varga-Fekete T, Puskas A, Kelemen P, Brassai Z, Szekeres-Csiki K, Gombos T, Csanyi MC, Harsfalvi J. High circulating osteoprotegerin levels are associated with non-zero blood groups. BMC Cardiovasc Disord. 2016;16(1):106

50. Min HL, Morony S, Sarosi I, Dunstan CR, Capparelli C, Scully S, Van G, Kaufman S, Kostenuik PJ, Lacey DL, et al. Osteoprotegerin reverses osteoporosis by inhibiting endosteal osteoclasts and prevents vascular calcification by blocking a process resembling osteoclastogenesis. J Exp Med. 2000;192(4):463-74.

51. Collin-Osdoby P. Regulation of vascular calcification by osteoclast regulatory factors RANKL and osteoprotegerin. Circ Res. 2004;95(11):1046-57.

52. Pritzker LB, Scatena M, Giachelli CM. The role of osteoprotegerin and tumor necrosis factor-related apoptosis-inducing ligand in human microvascular endothelial cell survival. Mol Biol Cell. 2004;15(6):2834-41.

53. Zauli G, Corallini F, Bossi F, Fischetti F, Durigutto P, Celeghini C, Tedesco F, Secchiero P. Osteoprotegerin increases leukocyte adhesion to endothelial cells both in vitro and in vivo. Blood. 2007;110(2):536-43.

54. Secchiero PL, Corallini F, Pandolfi A, Consoli A, Candido R, Fabris B, Celeghini C, Capitani S, Zauli G. An increased osteoprotegerin serum release characterizes the early onset of diabetes mellitus and may contribute to endothelial cell dysfunction. Am J Pathol. 2006;169(6):2236-44.

\section{Submit your next manuscript to BioMed Central and we will help you at every step:}

- We accept pre-submission inquiries

- Our selector tool helps you to find the most relevant journal

- We provide round the clock customer support

- Convenient online submission

- Thorough peer review

- Inclusion in PubMed and all major indexing services

- Maximum visibility for your research

Submit your manuscript at www.biomedcentral.com/submit 